\title{
LA DIFERENCIA INTERNA
}

\author{
Adolfo Chaparro Amaya* \\ doi: 10.11144/Javeriana.uph37-74.ldid
}

\section{RESUMEN}

En este artículo se exploran las fuentes del concepto de diferencia establecido por Deleuze y, en particular, la idea de una diferencia no fenomenológica, entendida como diferencia interna. En la primera parte, se rastrea la apropiación que Deleuze hace de los conceptos de memoria y duración propuestos por Bergson, como si allí hubiera una respuesta a la sistematización heideggeriana de Nietzsche, abriendo el concepto de fuerzas a otros como heterogeneidad, relatividad y multiplicidad. En la segunda parte se aborda la hipótesis según la cual de la inmersión en las síntesis bergsonianas del tiempo surge (i) la justificación para la reformulación del eterno retorno desde la repetición, (ii) el problema propiamente deleuziano de la diferencia interna y (iii) el concepto de virtual como la cifra definitiva de un nuevo plano de inmanencia para el pensamiento. Finalmente, a modo de conclusión, se presenta la diferencia interna desde el afuera que la desborda y la hace mutar en el conjunto de la filosofía deleuziana.

Palabras clave: diferencia interna; fuerzas; duración; repetición; virtual 


\title{
THE INTERNAL DIFFERENCE
}

\begin{abstract}
This article explores the sources of the concept of difference advanced by Deleuze and, in particular, the idea of a non-phenomenological difference, understood as internal difference. In the first part, Deleuze's appropriation of the concepts of memory and duration proposed by Bergson is explored, as if it corresponded with a response to Heidegger's systematization of Nietzsche, thus opening the concept of forces to others such as heterogeneity, relativity, and multiplicity. The second part contains a dicussion of the hypothesis according to which the immersion in the Bergsonian synthesis of time results in (i) the justification for the reformulation of the eternal return as repetition, (ii) the distinctively deleuzian problem of internal difference, and (iii) the concept of virtual as the definitive sign of a new plane of immanence for thought. $\mathrm{T}$ - he article concludes by presenting the internal difference from the outside that overflows it and makes it mutate in the whole of Deleuzian philosophy.

Keywords: internal difference; forces; duration; repetition; virtual
\end{abstract}


EN LA TRADICIÓN FENOMENOLÓGICA, la ontología de la diferencia ha tenido como referencia y límite la diferencia natural, visible, observable que distingue las cosas - las fuerzas, la materia, los seres vivos y los humanos-. En cada uno de esos ámbitos, el fenomenólogo puede registrar diferencias de intensidad y grado, o diferencias específicas que pudieran ser descritas como el contenido de un cuadro general de lo visible y lo representable. Desde sus primeros textos, inspirado en Bergson, Deleuze (1956/2005a, p. 47) deja la descripción científica y fenomenológica en suspenso, advirtiendo que en ella se tratan las diferencias de naturaleza espacio-temporal, de género y especie, o de intensidad respecto de las fuerzas, pero no la diferencia interna que le compete a la filosofía ${ }^{1}$. Según este argumento, mientras el análisis filosófico se mantenga en una "relación negativa" con las cosas, no trasciende la reflexión exterior que le otorga la universalidad genérica propia de la ciencia, y termina por confundir las diferencias de naturaleza con la pregunta por la naturaleza de la diferencia. En esa etapa, y en lenguaje husserliano, para Deleuze (2005a) el acceso a la naturaleza de la diferencia supone una "relación positiva y directa con las cosas", en la medida en que la filosofía pretende captar la cosa misma a partir de lo que ella es, solo que ahora la "cosa misma" es definida "en su diferencia con respecto a todo lo demás, es decir, en su diferencia interna” (p. 46).

Desde 1956 a 1962 se produce un significativo silencio en la obra de Deleuze. En 1962 se publica Nietzsche y la filosofía, sin que aparezca el concepto de diferencia interna. Sin embargo, allí se establece la lectura del eterno retorno de lo mismo como retorno de la diferencia. En lugar de interpretar la diferencia interna en un plano metafísico o subjetivo, Deleuze inscribe el concepto en un empirismo superior que convoca el despliegue nietzscheano de las fuerzas (físicas, psíquicas, naturales) en términos de distancia, interpretación y valoración. La valoración que supone la fuerza en Nietzsche implica una serie de relaciones, selecciones y jerarquizaciones, esto es, un sentido potencial que desborda la descripción fenomenológica. A continuación, el trabajo sobre las series hermafroditas en Proust y los signos (1964/1995) anuncia los temas de la repetición vestida y el despliegue de un plan de inmanencia significante que hace indiscernible el signo

1 En las primeras citas de cada texto, introduzco las fechas de la edición original entre corchetes con el fin de precisar la genealogía del concepto de diferencia interna en Deleuze. 
y la presencia, la serie y las singularidades, la identidad y la diferencia, la copia y el original. Un paso más: en Spinoza y el problema de la expresión (1967/1975), Deleuze pone en primer plano la expresión como la concrescencia de la emanación interna a través de la cual los atributos expresan la sustancia, mientras los modos expresan la composición específica de los atributos, llevando al límite el argumento de que la sustancia resulta indescriptible por fuera de sus expresiones. Finalmente, en Diferencia y repetición (1968/2002) todas esas lecturas se cruzan y esta obra se convierte, para nosotros, en el cierre del arco que comienza con el artículo sobre Bergson de 1956. Ya tendremos tiempo de examinar el que sería el primer libro "propiamente" deleuziano que no tiene un objetivo monográfico, sino programático. Por ahora solo quisiera señalar una paradoja que lo atraviesa: mientras en Spinoza lo más interno, la sustancia divina, es expresable en los modos singulares, en Nietzsche lo más superficial hace parte de una valoración de la vida, de una hermenéutica de las fuerzas que va más allá de lo propiamente humano en términos de voluntad de poder. En uno y otro caso se explora la idea de un empirismo superior que excede la descripción objetiva de los modos y la cuantificación de las fuerzas. Al involucrar la expresión en la potencia spinozista y la valoración en la voluntad de poder nietzscheana, Deleuze (2005a) no cesa de plantear estrategias filosóficas capaces de "elevar la diferencia a lo absoluto" (p. 54) por el recurso a la exploración sistemática de la diferencia interna.

Hay varias maneras de avanzar en la genealogía de un posible concepto de diferencia interna. Señalemos dos. La primera tiene que ver con la posible lectura que Deleuze pudiera haber hecho del Nietzsche de Heidegger (1961/2013), sea directamente del alemán o en las traducciones fragmentarias que ya había empezado a publicar Pierre Klossowski desde 1967, pero cuya traducción completa solo sería publicada en francés en 1971. Es verdad que Deleuze no hace referencia al texto, pero no deja de haber señales contradictorias. Si bien se podría decir que en principio Deleuze y Heidegger concuerdan en la trascendencia de Nietzsche para la historia de la filosofía, en el texto de Deleuze está implícita la crítica al intento de sistematización que propone Heidegger. Por ahora, diríamos que la virtud -y la dificultad insalvable- de Heidegger es haber partido de una formulación esencialista del eterno retorno que termina por fundar una metafísica radicalmente ajena al proyecto deleuziano de un empirismo superior. La otra dificultad tiene que ver con la influencia de Bergson, tan evidente y tan difícil 
de discernir del pensamiento del propio Deleuze. En la idea de una filosofía de la diferencia que piensa la multiplicidad de lo viviente como el ser problemático por excelencia y el devenir como la dimensión de lo vivo a través de la individuación, no es fácil distinguirlos. Para Éric Alliez (1998), la filosofía deleuziana no se concibe más que "a partir de un bergsonismo spinozista que pone la necesidad del sistema (del concepto) como heterogénesis (de la vida)” (p. 264)². Mi sospecha es que esa inspiración en torno a lo viviente es tan importante como la publicación de Las palabras y las cosas de Foucault en 1966, donde aparece formulado el empirismo trascendental que, a mi juicio, hace plausible para Deleuze la pertinencia epistémica de un empirismo superior que sustituya las condiciones de toda experiencia posible (Kant) por las condiciones de la experiencia real.

Ahora bien, este texto no se propone reconstruir a Spinoza, Nietzsche, Heidegger o Bergson alrededor de Deleuze, sino establecer una genealogía del concepto de diferencia interna a partir de las relaciones que Deleuze tiene con cada uno de ellos. Desde luego, es inevitable reconstruir pasajes de esa historia que den un panorama de la matriz programática de la filosofía deleuziana que subyace a Diferencia y repetición, pero no es ese el objetivo central. El plan es el siguiente. En la primera parte, sigo la apropiación que Deleuze hace de los conceptos de memoria y duración propuestos por Bergson, como si allí hubiera una respuesta no metafísica a la sistematización heideggeriana de Nietzsche, abriendo el concepto de fuerzas a otros como heterogeneidad, relatividad y multiplicidad. En la segunda parte trabajo la hipótesis según la cual de la inmersión en las síntesis bergsonianas del tiempo surge (i) la reformulación del eterno retorno desde la repetición, (ii) el problema propiamente deleuziano de la diferencia interna y (iii) el concepto de virtual como la cifra definitiva de un nuevo plano de inmanencia para el pensamiento. Finalmente, presento la diferencia interna desde el afuera que la desborda y la hace mutar en el conjunto de la filosofía deleuziana.

La idea es que el propio Deleuze traza una línea de fuga hacia el afuera, transformando la diferencia interna en el pretexto para una ontología relacional -entre materia y espíritu, entre adentro y afuera, entre virtual y actual, entre diferencia y repetición- en la que anuncia ya el in-between como un rasgo central de

2 Las citas en francés de Alliez, Orlandi y Danowski, tomadas del texto editado por Eric Alliez (1998), han sido traducidas por el autor. Igual, la cita de Smith, C. (2015). 
su filosofía. De ahí la hipótesis del arco que se abre con el texto de 1956 sobre Bergson y se cierra en 1967, en cuanto que después de Diferencia y repetición desaparece el concepto de diferencia interna y, a cambio, $s e^{3}$ genera una serie de creaciones conceptuales que, a mi juicio, vienen a operar como simulacros de esa primera formulación.

\section{De la totalidad a la uno/Multiplicidad}

EN TÉRMINOS DE MÉTODO, la diferencia interna opera en principio como una suerte de puesta entre paréntesis de la evidencia fenomenológica, con lo cual pone a trabajar a la suspensión del juicio en contra de su propia matriz epistemológica. La cuestión es que la negación de la evidencia de la diferencia como identidad representable no tiene pretensiones escépticas, sino todo lo contrario. Lo que pretende Deleuze es abrir el espacio impensado de una dramatización de las fuerzas en su intensidad ${ }^{4}$, en su duración o en su interrelación, cuyos efectos no son inmediatamente descriptibles. Este rechazo de "ir a la cosa misma" se compensa a lo largo de Diferencia y repetición con la propuesta de una ontología donde la duración, lo virtual, o los topos adquieren primacía frente a la materia, el ente o el espacio. Buena parte de esta nueva ontología propone un plano de inmanencia donde coinciden Spinoza y Bergson, pero resulta imposible de expresar sin recurrir al concepto nietzscheano de fuerza. De ahí la importancia de Heidegger, quien en su lectura de Nietzsche propone el concepto de fuerzas como núcleo del eterno retorno, y el eterno retorno como el fundamento de una metafísica del devenir.

$\mathrm{Al}$ colocar las fuerzas como mediadoras entre el ser y el devenir, Heidegger instala la esencialidad del tiempo en el conjunto de su pensamiento. En una posible genealogía de la diferencia interna, se destaca cómo Heidegger diferencia las

3 El se advierte la dificultad de probar que se trata de una decisión deliberada y justificada por el propio Deleuze.

4 Desde muy pronto, Deleuze reconoce en Nietzsche el primero en haber pensado la intensidad como concepto: "En verdad, Nietzsche se interesaba por la física como ciencia de la cantidades intensivas, y contemplaba, más allá de ella, la voluntad de poder como principio <intensivo>, como principio de intensidad pura [...] en suma, extraer la forma superior de todo cuanto es (la forma de intensidad)" (2005b, p. 161). 
fuerzas de su representación científica, al tiempo que plantea una fuerza "abstracta", la cual, si bien emerge con ocasión de un $x$ externo al pensamiento, se define como lo que fuerza al pensamiento (2013, pp. 290 y ss.). El propio Deleuze trabajó en toda su obra reenfocando ese afuera del pensamiento más allá del objeto, al tiempo que replanteaba la idea misma de objeto del pensamiento. De la misma manera que lo importante en el eterno retorno es el retorno mismo y no la particularidad cosmológica o existencial de lo que retorna, lo importante de la externalidad en este caso es el afuera que señala al sujeto la necesidad de ir más allá de sí, "sin salir de sí", en un pulso constante con su propia potencia de pensamiento. Deleuze rescata esa diferencia interna entre objeto y afuera, aclarando que lo que está en juego en el estar fuera de si es la capacidad para otorgarle al pensamiento una finalidad más alta, la cual, igual que para Heidegger y Nietzsche, desborda el sí mismo y sus representaciones. Como veremos, la dificultad mayor de esa dualidad es cómo conjugar la temporalidad del Existente y la temporalidad del Ser en su conjunto, sin recurrir a una síntesis totalizadora producto de la fuerza metafísica del pensamiento. Por un lado, no es posible la representación del devenir, del cual solo tenemos la experiencia intangible y el conocimiento verbal; por el otro, una visión puramente totalizadora de las fuerzas tampoco parece satisfactoria.

Hay una manera de plantear el problema en términos cinéticos que, frente a Heidegger, pone a Deleuze del lado de Bergson'. El devenir, dice Bergson (1907/1985, pp. 264, 269), "simboliza una determinada transición" de la cual es posible tomar unas instantáneas, sin que se pueda decir nada sobre las variaciones que sufre un cuerpo en movimiento a cada instante. La forma "pertenece a lo inmóvil”, mientras que la realidad es movimiento. Lo que parecía una pregunta epistémica se convierte en una observación ontológica, con lo cual la realidad ya no es la instantánea de la forma inmóvil, sino la transición implícita en el movimiento. Dicho de otra manera, la idea de tiempo es todavía demasiado epistémica para avanzar en el diagnóstico que supone la valoración de la vida en su propio devenir. En el proyecto deleuziano, ese límite indica que las fuerzas tienen

5 Sorprende la lectura que Sloterdijk (2011) hace de Heidegger como el filósofo del Dasein en movimiento que lleva a cabo "la transformación de la metafísica en onto-cinética" (p. 24), cuando es el propio Sloterdijk el que realiza la deconstrucción antropotécnica de la metafísica, y se encarga de de su explicitación. 
que pasar la prueba del empirismo superior, ya que las descripciones que ofrece la ciencia son indispensables, pero no suficientes, para pensar lo impensado: tanto del concepto como de las fuerzas en devenir. En nietzscheano, se plantea la tarea de abordar "lo infinito del movimiento real como la diferencia absoluta en la repetición del eterno retorno" (Deleuze, 2002, p. 33). Para ello, es necesario poner en evidencia la capacidad que tiene cada fuerza "de seleccionar, de expulsar como de crear, de destruir como de producir, y no de suscitar la vuelta de lo Mismo en general" (Deleuze, 2002, p. 33). Para pensar ese plus indeterminado de la fuerza Deleuze propone descubrir en la naturaleza la voluntad de quererse como physis, en una instancia superior "a sus propios reinos y a sus propias leyes" (Deleuze, 2002, p. 33). Así, lo que parece un impulso trascendental funciona como un postulado general del método a seguir para trazar la diferencia entre repetición del eterno retorno de las fuerzas y generalidad de las leyes naturales, en los límites de su singular empirismo superior en construcción.

Para fundar adecuadamente ese tipo de cuestiones como problemas, en Diferencia y repetición Deleuze sugiere una fórmula derivada de la lectura de Spinoza: donde se dice el ser habria que decir pluralidad (de atributos) y multiplicidad (de modos). En esa lectura, Deleuze afirma su preferencia por el terreno de la Sustancia (Spinoza) frente al del Ser (Heidegger). Establecido el plano de inmanencia (spinozista) para las fuerzas (nietzscheanas), Deleuze pregunta por los conceptos que lo recorren y, sin citarlo, repite a su manera el repertorio conceptual que le ha permitido a Heidegger sistematizar la doctrina del eterno retorno: movimiento, fuerzas, diferencia, repetición. Los conceptos claves de Nietzsche no son tantos, así que no había opción, pero la diferencia está, como diría Heidegger, en los criterios que permiten orientar el pensamiento; o, como diría Deleuze, en la imagen que cada uno de los tres tiene para el plano de inmanencia donde se despliegan los conceptos. Al explorar el plano de inmanencia donde se despliegan las fuerzas cambia el sentido y el alcance de las preguntas: “idónde está el movimiento? ¿En la esfera del espíritu o en las entrañas de la tierra, que no conoce ni Dios ni yo?" (Deleuze, 2002, p. 35). Ese modo de preguntar afecta radicalmente el antropocentrismo de los conceptos posibles. En lenguaje spinozista, se trata de entrar por el medio de las fuerzas (atributos), como si las fuerzas fuesen el medium relacional entre los modos (individuales) y la sustancia (absoluta). Por principio, modos, atributos y sustancia gozan de su propia infinitud, 
pero es distinta la infinitud en su "uso real", empírico, que la infinitud bloqueada artificialmente por su "uso lógico". Deleuze advierte que una comprensión débil del infinito es más adecuada para la exposición finita de los sistemas de fuerzas. Mientras el "bloqueo" lógico de la infinitud finalmente hace inocua la repetición, cuando se consideran extensiones discretas "la repetición es el hecho puro de un concepto de comprensión finita, obligado a pasar como tal a la existencia"; con lo cual, tenemos "un pulular de individuos absolutamente idénticos en cuanto al concepto", previstos en el uso lógico, pero que ahora "participan de la misma singularidad existencial" (Deleuze, 2002, p. 38).

Como afirma Philippe Mengue (2008), las leyes de la naturaleza son también las leyes del cambio universal, así que "una verdadera repetición sería del orden del milagro". No es suficiente "sustituir un orden de generalidad por otro (una igualdad por una semejanza)" (p. 226), para dar cuenta del poder singular que plantea la repetición. Este es un punto de inflexión en la divergencia entre Deleuze y Heidegger, en cuanto precisa el plus deleuziano que excede la descripción científica sin negarla, al sugerir que las generalidades de los ciclos en la naturaleza "se develan como la máscara de las singularidades que asoman a través de sus interferencias" (Deleuze, 2002, p. 56). En realidad, la misma conclusión ya estaba esbozada en relación con la ley moral, ya que, bajo las generalidades del hábito en la vida moral, encontramos los modos singulares de existencia, en los cuales Kierkegaard supo distinguir repetición de generalidad, haciendo de la repetición un movimiento diferenciador. Simplificando en su fractalidad los dos aspectos del problema, Deleuze establece diferencia y repetición como movimientos interiores a la idea, no al concepto entendido como representación general, con lo cual, "la repetición no existe sin idea, sin una diferencia interna que ella comprende, desplaza y disimula, en los diferentes momentos de un dinamismo repetidor y creador" (Mengue, 2008, p. 225). En adelante, ese será el recurso metódico, el paso de ida y vuelta entre la generalidad y la multiplicidad empírica, efectiva, experimentable, entre diferencia genérica y diferencia específica, entre el concepto sin diferenciación y la genética inmanativa de las fuerzas "sin" concepto. ¿Cómo representar entonces un tipo de repetición "desnuda" que corresponda a esta ausencia de concepto? Deleuze inventa los disfraces que acompañan la repetición, para lo cual retoma el esquematismo con que Freud concibe la dinámica interior de la repetición traumática a partir del desplazamiento, la condensación y la 
dramatización. En esa operación aconceptual encuentra una instancia prerrepresentativa que hace indistinguible la repetición de sus disfraces en una suerte de traslape continuo de lo significante con lo asignificante que comporta la génesis de la representación. Como concluye Mengue (2008), la repetición "se disfraza constituyéndose y se constituye disfrazándose [...]. La verdadera repetición no puede preexistir a la repetición desnuda o bruta, porque se produce y se envuelve en ella" (p. 230). En Diferencia y repetición, al establecer la anterioridad de la repetición pura respecto de la repetición pensada, Deleuze (2002) dramatiza la topología del problema concibiendo la repetición activa como una puesta en escena adonde las fuerzas y los signos acuden en su indeterminación:

En el teatro de la repetición se experimentan fuerzas puras, trazos dinámicos en el espacio que actúan sobre el espíritu sin intermediarios, y que lo unen directamente a la naturaleza y a la historia, un lenguaje que habla antes de las palabras, gestos que se elaboran antes de los cuerpos organizados, máscaras previas a los cuerpos, espectros y fantasmas anteriores a los personajes -todo el aparato de la repetición como potencia terrible (pp. 34-35).

En heideggeriano, seguiríamos hablando del sentido colectivo del ser y el juego de las diferencias en el ente. Pero para Deleuze (2002) ya no se trataba de encontrar el universal o el singular verdaderos, sino de desplegar el ser en su "sentido común distributivo", y la multiplicidad concomitante a los procesos de individuación como plano de expresión de la "diferencia general" (p. 444). Para trazar las divergencias de Deleuze con "el Nietzsche de Heidegger" vale la pena seguir el recorrido de esta deducción. En Nietzsche y la filosofía Deleuze (1986) había intentado establecer una matriz dialéctica del juego de las fuerzas que rebasara la oposición lógica y diera cuenta de la actividad de las fuerzas entendida como una relación dinámica entre fuerzas activas y reactivas, en la que las exigencias ontológicas y existenciales del eterno retorno parecían coincidir. Rápidamente, la exposición se fue decantando en una versión no dialéctica de la famosa oposición amo/esclavo. Al declinar la síntesis conceptual, en la oposición deleuziana emerge el sentido selectivo que la interpretación entendida como valoración le da al destino de las fuerzas. Pero, en definitiva, Deleuze no logra todavía desatar la multiplicidad de las fuerzas. Un resto hegeliano ligado a la mediación de lo negativo (universal) retiene esa multiplicidad, y hace impensable la 
diferencialidad que se deriva de las relaciones entre las fuerzas. Sin embargo, el texto propone dos axiomas claves en nuestra genealogía que anuncian el enfoque de Diferencia y repetición. El primero dice que "la voluntad de poder es el elemento diferencial de la fuerza” (Deleuze, 1986, p. 15); el otro afirma que, sea cual sea la calidad de la fuerza, la voluntad "no se ejerce misteriosamente sobre una materia en general, sino que, necesariamente, se ejerce sobre otra voluntad” (p. 15). La pregunta es si -y cómo- la estructura heterogénea de las voluntades escapa/ría a la relación entre mandar y obedecer. Deleuze insiste en que de esa oposición no se deriva una dialéctica, pero en la medida en que toda fuerza tiene a otra fuerza como objeto no se ve cómo salir fácilmente del círculo entre acción y reacción sin una sintesis -aunque fuese dinámica, distributiva y no conceptual- que presente la concrescencia ${ }^{6}$ de cada modo, ente o proceso de individuación.

En contravía de la vía platónica, en la cual, por contraposición a la Idea, la diferencia permanecía en "una concepción de diferencia aún externa", Deleuze plantea abiertamente la diferencia "en símisma"; y en oposición a la vía hegeliana de la dialéctica de la contradicción, en la cual la diferencia se difumina en un tipo de negación abstracta recuperada por el concepto, ya en "La concepción de la diferencia en Bergson”, Deleuze (2005a) había encontrado una salida que anuncia el paso del texto sobre Nietzsche a Diferencia y repetición. En ese texto, claramente bergsoniano, afirma que (i) "la duración es la diferencia consigo misma", (ii) la memoria es la coexistencia de los grados de diferencia" y (iii) "el impulso vital es la diferenciación de la diferencia” (p. 60). Al adoptar el vitalismo de Bergson, Deleuze renuncia a la Idea como verdad (Platón) y a la dialéctica como síntesis reflexiva (Hegel), asumiendo una interpretación radicalmente materialista de las fuerzas y un método ajeno al esencialismo nominalista y anticientífico de Heidegger. El argumento contra Hegel es que no hay una potencia de lo

6 El efecto de la filosofía de Whitehead (1929/1995) en Deleuze durante el período que nos ocupa está aún por aclararse. Es perceptible en los términos, en la lógica de los razonamientos, en la formulación de los problemas. Baste por ahora recoger una cita donde el concepto de concrescencia, como es tan propio de su estilo, convoca los de creatividad, transición o mundo actual, entre otros: "La creatividad en virtud de la cual cualquier mundo actual relativo completo es, por la naturaleza de las cosas, el dato para una nueva concrescencia, se denomina 'transición.' Por lo tanto, en virtud de la transición, 'el mundo actual' es siempre un término relativo, y se refiere a esa base de ocasiones actuales presupuestas que es un dato para la nueva concrescencia” (Whitehead, 1956, p. 288). 
negativo respecto de la fuerza afirmativa tal que, a continuación, la oposición pudiera resolverse en un tipo de diferencia/identidad entendido como síntesis de fuerzas activas y reactivas. Dicho de otra manera, las fuerzas en su concreción múltiple y diferenciada son afirmativas, en el mismo sentido que los modos spinozistas se expresan en su singularidad, más allá de los atributos que los componen ${ }^{7}$. Los efectos no expresan necesariamente los elementos causales que los hacen posibles. Por lo demás, las pautas genealógicas del enfoque perspectivista ya están en la doctrina original del eterno retorno. Allí, Nietzsche (1932) se plantea la búsqueda de grados cuantitativos (intensivos) y cualitativos (temporales) de diferenciación y repetición de las fuerzas, bajo el presupuesto de que el origen de las cualidades presupone el de las cantidades y que las cantidades "pudieron

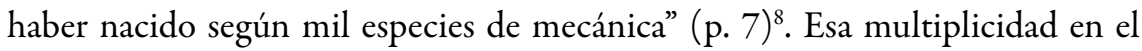
origen aplica igualmente para las leyes químicas y para las formas orgánicas, a las que considera "inexplicables en su origen Uno". Es posible, dice, suponer "una energía de contracción uniforme en todos los centros de fuerza del universo", pero la hipótesis resulta incompatible con "la pluralidad y el desorden del mundo" (p. 7). En definitiva, la diferencia es impensable desde un foco uniforme de desarrollo del universo. Al renunciar a una estructura "en la que se manifestara de una forma obvia la unidad de una multiplicidad", Deleuze procede a distinguir entre una multiplicidad falsa, superficial, puramente exterior, cuantitativa, en la que prima la discontinuidad, y lo que concibe ahora como una "multiplicidad verdadera", interior, correspondiente al devenir diferenciado y diferenciador, "cuya aprehensión permitirá repensar lo real en sus caracteres cualitativos" (Smith, 2015, p. 34).

7 Si bien la crítica de Deleuze a Hegel ya es un lugar común, sigue resonando cierto paralelismo que no deja de problematizar la divergencia. Además de las nociones totalizantes de absoluto y devenir, que se refractan en varios sentidos al comparar los dos autores, en términos lógicos valdría la pena examinar desde Deleuze tres principios hegelianos: (i) la singularidad solo es posible a través de la intuición, (ii) el universal que subsume lo particular no se agota en el individuo que lo presenta, (iii) el universal es absolutamente múltiple (Hegel, 1980, p. 127).

8 No es mi intención valorar aquí la autenticidad de los textos sobre la doctrina del eterno retorno editados por la hermana de Nietzsche; pero sí reconocer el trabajo pionero de Heidegger para establecer la secuencia de la doctrina en el conjunto de su obra y, especialmente, en Asi habló Zaratustra (2003) y El gay saber (1986, por ejemplo en p. 232). 
Deleuze no dejará de volver sobre la "doctrina" del eterno retorno para matizarla y radicalizarla, como un antídoto frente a las distintas formas de la dialéctica que no dejan de ofrecer los buenos servicios del sentido común y de la representación más o menos compleja de la diferencia. Frente a la representación de las diferencias empíricas entre las cosas, Deleuze insiste en el ejemplo del relámpago en la noche "como una cosa que se distingue de un fondo y que permite ver al ser en su diferenciación diferenciante” (Mengue, 2008, p. 232). Mientras la diferencia externa separa una cosa de otra, la diferencia interna reenvía lo que diferencia a su propia diferencia en términos del ser y el pensamiento. No es fácil hacer compatible esta constante diferenciación de la diferencia con la regularidad que percibimos en el comportamiento de las grandes fuerzas del universo, de los cuerpos celestes o de los organismos, pero Deleuze saca provecho conceptual de esa dificultad para postular una doble diferencia que dé cuenta de la diferencia ontológica (différenciation) y de la diferencialidad diferenciante de las fuerzas (différentiation). La primera encuentra su límite en la identidad de las diferencias, mientras la segunda establece la diferencia misma de lo que retorna, asumiendo que lo que retorna, en última instancia, es el retorno mismo, sin destino ni finalidad conocida. La creación de una segunda acepción de la diferencia -no diferenciada en su identidad sino diferenciante en su repetición-, le permite a Deleuze hacer el tránsito de la pluralidad deducida desde la diferencia ontológica y empezar a explorar la heterogeneidad de lo que desde Bergson podríamos llamar la pluralidad intuida.

Si bien la intuición tiene el descrédito del psicologismo, para Bergson la psicología constituye una entrada en la ontología, una forma de instalarse en el Ser. Es verdad que la duración psicológica, "nuestra duración", se intuye directamente, pero no es más que una duración "dentro de una infinidad”; y es justo por eso que la multiplicidad de duraciones del Ser no nos impide "hablar de un monismo en la medida en que todo es duración" (Deleuze, 1966/1996, p. 80). Se empieza por semejanza describiendo la duración de los seres humanos, luego percibimos la que acontece en los demás seres vivos, y así vamos ampliando el registro a la pluralidad de duraciones desplegada por todo el universo. En principio, no parece impropio encontrar una equivalencia conceptual entre duración e interioridad como predicados de la diferencia, pero en lugar de explicar esta coincidencia, Deleuze avanza en lo que a su juicio es realmente problemático. Dado que 
para Bergson no tiene sentido la hipótesis de una multiplicidad de duraciones, Deleuze decide examinar la hipótesis de un monismo del tiempo, esto es, "un tiempo único, una duración única de la que todo participaría, incluida nuestra consciencia, los seres vivos y la totalidad del mundo material (Deleuze, 1996, p. 81$)^{9}$. Al adoptar el monismo, más que la postulación de un axioma, lo que está en juego es la imposibilidad de pensar el tiempo con el esquema oposicional objetivo/subjetivo, activo/reactivo, a priori/a posteriori. Se necesita otro lenguaje, otra lógica, otros procedimientos conceptuales para descubrir, al mismo tiempo, lo que hay de devenir en la multiplicidad de lo ente, y para dar cuenta de la temporalidad propia de los problemas que retornan a la filosofía.

Para decirlo programáticamente, lo que procede es renovar la pregunta por el tiempo desde la multiplicidad, entendida como plano de inmanencia de la totalidad. Desde Heidegger, el existente existe para la filosofía, es de por sí una experiencia de la temporalidad que abre a la pregunta por el Ser. La yección, entendida como la respuesta activa del Dasein en tanto que destinado, es a la vez una experiencia y una pregunta por el tiempo vivido. En esa experiencia, lo que llamamos la identidad original del sujeto adquiere el poder de diferenciarse sin desconocer, en otros planos, la repetición cualificada del tiempo cósmico, del tiempo del saber o del tiempo social entendida desde su relación y su no relación con el trascurrir de la existencia. El punto es que la impronta fenomenológica hace que Heidegger termine por "negar conservando y superando" la intencionalidad para llevarla a un plano ontológico, esto es, el que compromete la comunidad de sentido entre las dimensiones actualizadas del ser. Es por eso que, para Heidegger, las diferenciaciones solo prueban la igualdad y la neutralidad del Uno. Para Badiou (1997), Heidegger habría subvertido la intencionalidad y la consciencia solo en apariencia, con lo cual, no solo impide la síntesis disyuntiva que supone la síntesis de la relación y la no-relación sino que, en definitiva, "no asume las consecuencias de la univocidad del ser" (pp. 40-42).

9 Me permito citar una de entre las múltiples aproximaciones de Bergson a la relación entre memoria y duración: "La memoria, prácticamente inseparable de la percepción, intercala el pasado en el presente, contrae a su vez en una intuición única múltiples momentos de la duración, y de este modo, por su doble operación, es causa de que percibamos de hecho la materia en nosotros, cuando de derecho la percibimos en ella" (2006, p. 84). 
La sospecha de Deleuze es que el compromiso con la experiencia lleva a Heidegger a un antropocentrismo sin retorno. De ahí su adopción del modelo bergsoniano, en el cual la contracción puntual del tiempo en el presente de los individuos es a la vez una afirmación ontológica y una intuición existencial. Se trata de hacer hablar al ente en su totalidad desde la multiplicidad, en continua diferenciación interna. El desplazamiento de los conceptos heideggerianos relativos al Ser al ámbito de la Multiplicidad hace justicia al propio Nietzsche. Pero, sobre todo, le permite a Deleuze seguir la certeza inicial de que los movimientos de expansión y contracción del cosmos pueden ser predicados también del individuo, concebido como un modo en el que las pasiones tristes y alegres inciden con una potencia similar de expansión y contracción. Esa concepción mixta del tiempo, a la vez empírica e imperceptible, pasiva y activa, co(i)mplicada en la ontología de las singularidades múltiples, es ya propiamente deleuziana, pero para muchos no deja de evocar la originariedad heideggeriana. A mi juicio, la ruptura es más directa: ya no es posible volver al carácter esotérico o esencialista de la doctrina del eterno retorno. Deleuze encuentra que la doctrina tiene una expresión exotérica que conecta con los desarrollos de la física y la matemática, y que en esa exploración concurren tanto la multiplicidad del espaciotiempo propuesta por Einstein como la geometría no euclidiana que la inspira. Ya es claro que el tiempo no se reduce al movimiento, pero el puro concepto de devenir infinito desprovisto del movimiento finito parece condenado a la tautología. Siguiendo al Einstein de Bergson, Deleuze (1996) asume el tiempo como una cuarta dimensión que dinamiza las tres dimensiones del espacio, con lo cual al final tenemos "una multiplicidad de tiempos que transcurren con velocidades diferentes" (p. 83), cada uno inscrito en su propio sistema autorreferencial, en una formulación cercana a los bloques de espaciotiempo einstenianos, pero diferenciados potencialmente al infinito, en tanto en cuanto son "inconcebibles si no se les atribuye una repetición en lo más profundo de sí” (Mengue, 2008, p. 234).

Afirmada la multiplicidad del espacio-tiempo, Deleuze (1996) se pregunta de nuevo por la consistencia del "tiempo único, universal e impersonal” (p. 83) que defiende Bergson. El punto para Bergson, dice Deleuze, es que la descripción de las multiplicidades -actuales, numéricas, discontinuas- de la teoría de la relatividad no dan cuenta de "las multiplicidades virtuales, continuas y cualitativas" (1996, p. 83) que le dan al tiempo su propia diferencialidad, irreductible a 
los bloques en los que se tiende a confundir el tiempo con el espacio. Anunciando lo que se conoce como ontología de lo virtual, Alliez (1998) destaca dos operaciones de la dupla Bergson/Deleuze: (i) "el cálculo infinitesimal es investido metafísicamente a fin de comandar la ontología, dándole el giro característico de una heterogénesis", y (ii) se introduce el tiempo, "en un mismo movimiento constituyente y diferenciante, tanto del ser como del pensamiento" (p. 251). En esa conclusión no se pone en juego el alcance de la física para solucionar los problemas filosóficos, sino la potencia del pensamiento. Igual que Heidegger, Bergson se resiste a reducir el tiempo a la descripción calculada de sus variaciones espaciales y, dado que la duración psicológica es la única que los humanos podemos experimentar directamente desde dentro, termina por otorgarle a la atención la capacidad de "repartirse sin dividirse, de ser una y muchas" (Deleuze, 1996, p. 83). De repente, surgen varias preguntas constitutivas, entre otras: ¿es irrelevante la pregunta por si hay una o varias duraciones?, ¿la variedad se diferencia en una segunda instancia de acuerdo a los grados de intensidad, de distensión y de contracción que la expresan?, ¿cuál es el sentido de la duración? Por ahora, dejo las preguntas en suspenso para escuchar una respuesta más sencilla y profunda del propio Deleuze (1996):

El correr del agua, el vuelo del pájaro, el murmullo de mi vida, forman tres flujos; pero lo son porque $m i$ duración es uno entre ellos y además el elemento que contiene a los otros dos. En ese sentido mi duración tiene esencialmente el poder de revelar otras duraciones, de englobar a las demás y de englobarse a si misma hasta el infinito (p. 84).

En otros términos, se puede hablar de una infinidad de flujos actuales que participan del mismo todo virtual, en tanto en cuanto "la duración como multiplicidad virtual es ese Tiempo único” (Deleuze, 1996, p. 86). Para Deleuze, se puede afirmar la diversidad de tiempos en cada uno de los bloques de espaciotiempo einstenianos, pero a condición de afirmar, a la vez, la duración interior a cada uno de ellos. Por ello, en lugar de deducir la pluralidad de tiempos de la relatividad, como si se tratara solamente del cálculo que le corresponde a cada bloque, Deleuze (1996) insiste en una temporalidad interna que permite expresar lo vivido y lo vivible, reafirmando la duración bergsoniana como "coexistencia virtual de todos los grados de variación en un único y mismo tiempo" (p. 89). 
Por esa vía, Deleuze lleva al límite la tesis de Bergson sobre la realidad de lo virtual, forzando el pensamiento a concebir la existencia virtual de lo virtual como una gigantesca memoria, una suerte de cono universal invertido sobre el eje puntual de cada individuación, donde todos los pasados coexisten con diferencias de nivel relacionadas entre sí. En lo sucesivo, todos los niveles de referencia memoriosa, los grados de distensión y contracción de la materia, y los puntos de condensación del tiempo que se proyectan desde cada individuo, existen en tanto hacen indiscernible el presente actual de la virtualidad que le corresponde. El Presente y lo Virtual coexisten en la simplicidad de un tiempo único, "forman las partes en potencia de un todo virtual. Son la realidad de este virtual: el Presente" (Deleuze, 1996, p. 105). Badiou (1997) ha objetado esta idea de un tiempo único con el argumento de que el ente quedaría expuesto "a la irrealidad, a la indeterminación, a la inobjetabilidad" (p. 79) por arte de lo virtual, interpretado desde esa extraña extensión de lo real. La idea de Badiou es que lo virtual tiene ahora el rango de fundamento y, en esas condiciones, hace inviable la univocidad del Ser-Uno. A medida que Deleuze intenta arrancarlo, dice, es lo actual o el ente lo que se irrealiza, se indetermina y finalmente se inobjetiva, se desdobla fantasmáticamente. De repente estamos en otra ontología, en la que resucitan los entes discontinuos y las leyes generales, pero donde los grados y las intensidades propios de cada proceso de individuación -que es lo que finalmente se dice unívocamente de todos los seres en su constante repetición y diferenciación- ha desaparecido ${ }^{10}$. Lo virtual, en ese sentido, no es el opuesto simétrico de lo actual, lo que haría proliferar una dualidad inesperada. Ni la salida es volver a un empirismo de las multiplicidades vaciadas de fundamento. Ahora, el empirismo superior no solo es una afirmación de lo múltiple sino un reconocimiento ontológico de lo virtual, tan real como las palabras, las intensidades, los sueños o lo imperceptible. Lo más importante es que, de Bergson a Deleuze, se ha encontrado el camino para ontologizar el tiempo, dándole a la memoria como totalidad del pasado una "forma de ser", de modo que el plano de inmanencia no sea simplemente una cartografía imaginada del pensamiento, sino una duración indiscernible de cada campo espaciotemporal.

10 No debe olvidarse en la discusión el axioma por el cual, "lo esencial de la univocidad no es que el Ser se diga en un único y mismo sentido, sino que se diga, en un mismo y único sentido, de todas sus diferencias individuantes o modalidades intrínsecas" (Deleuze, 2002, p. 72). 
Desde luego, todo ello es más fácil de argumentar recurriendo al vitalismo que parecen compartir Bergson y Deleuze. Para Alliez (1998), establecida la inmanencia lo vivo y de lo vivido, la oposición de la vida y de la materia es desplazada, en un polo de la ecuación, por la "continuidad de duraciones" entre la materia y el espíritu (p. 257); y en el otro polo, por los modos -esto es, las individuaciones- que expresan la riqueza y la multiplicidad del devenir. Hay, sin embargo, al menos dos objeciones al vitalismo de esa solución que sugieren una salida propiamente deleuziana. La primera es que obliga a aceptar el élan vital bergsoniano como un relevo de la voluntad de poder y como una suerte de fundamento último de la totalidad de lo ente que, incluso, podría resolver la pregunta por la internalidad de la diferencia. Con una dificultad insalvable: élan vital no es un concepto que Deleuze utilice para esos propósitos en Diferencia y repetición. La otra objeción es que un principio vital, aun pensado como un atributo "espiritual" inscrito en lo más profundo de la materia, no deja de estar limitado a lo vivo. Al instaurarlo como principio, la "profundidad" no es más que una operación trascendental injustificada desde dentro del plano de inmanencia, con lo cual la crítica de Badiou a la uno/Multiplicidad estaría justificada. Pero frente a esta objeción de Badiou, y frente al propio Alliez, Deleuze (2002) insistirá en una errancia distributiva "en la que las cosas se despliegan sobre toda la extensión de un Ser unívoco y no repartido” (p. 73). Queda claro, entonces, que no es el ser el que se distribuye "según las exigencias de la representación", sino que todas las cosas se reparten en el Ser "en la univocidad de la simple presencia (el Uno-Todo)” (p. 73). Sugiero, entonces, volver al inicio, con la expectativa de que, avanzando en la diferencia interna como problema, podamos aclarar algunas de estas cuestiones metafísicas. Y no al contrario.

\section{Ontologizar el tiempo}

Desde un comienzo hemos tratado de seguir la advertencia de Deleuze de evitar la confusión entre las diferencias de naturaleza y la diferencia conceptual. Dado que la tematización más clara de lo "interno" es la diferenciación (différentiation) temporal, y justo allí está en juego la producción conceptual de la duración, podríamos sugerir una coincidencia entre conceptualizar la diferencia y establecer los alcances de la diferencia interna. No se trata de que conceptual e 
interior sean sinónimos, ni de que una diferencia material, perceptiva o deducida no pueda ser analizada desde un punto de vista conceptual. Simplemente, por las herramientas con que trabaja la filosofía, frente a la diferencia visible de las cosas en la naturaleza, Deleuze repara en una diferencia interna $a$ la duración que escapa a la descripción ontológica de lo ente. La tradición aristotélica inscribe la diferencia en el concepto en general, con lo cual, en adelante, la diferencia será tomada como modificación -corporal, empírica o extrínseca-, en cuanto se aloja del lado del accidente y no en la esencia. Si afecta la forma, y por tanto la esencia, la diferencia será establecida como diferencia de género. En el primer caso, la diferencia es demasiado "pequeña", y demasiado "grande" en el caso del género. Al final, para Deleuze (2002), "entre las diferencias genéricas y específicas se anuda el lazo de una complicidad en la representación" (p. 69). Esa tradición no cambia sustancialmente hasta la modernidad, con la salvedad de Leibniz, en la medida en que propone una diferencia intrínseca, distinta de la diferencia extrínseca, "fundada en un elemento diferencial intensivo que opera la síntesis de lo continuo en el punto para engendrar el espacio desde adentro" (Deleuze, 2002, p. 59).

Al simplificar el contraste de las dos diferencias, mientras la ciencia establece las diferencias de naturaleza con toda propiedad, la filosofía se ocupa de la diferencia interna atendiendo al proceso de diferenciación (différentiation) temporal, esto es, de los procesos de individuación en variadas escalas empíricas y registros de (in)visibilidad, y donde estaría la verdadera naturaleza de la diferencia. La cuestión es que, a falta de una descripción interna de la diferenciación (différentiation), Deleuze introduce el concepto de intensidad. Ese rasgo es lo que permite diferenciar una ontología de lo viviente de una fenomenología de lo vivido (Alliez, 1998, p. 258). Aunque sea motivo de tantas gradaciones, matices y posibilidades en obras posteriores, ya en Diferencia y repetición el proceso por el cual las intensidades determinan las diferenciaciones (différentiations) recibe el nombre de individuación. De ahí que toda individuación sea intensiva, porque la intensidad es individuante y las cantidades intensivas son factores individuantes (Orlandi, 1998, p. 65). En palabras de Deleuze (2002), la individualidad "afirma en sí la diferencia a partir de las intensidades que la constituyen” (p. 317 ${ }^{11}$.

11 Años más tarde, Deleuze (1978/2008) se sigue preguntando qué es la cantidad intensiva. Y se responde: "es lo que llena el espacio y el tiempo en tal o cual grado [...]. La aprehensión de la unidad 
En esa perspectiva, la filosofía de Deleuze asume el programa de una afirmación igualmente compleja del adentro y el afuera, incorporando las variantes entre interioridad y exterioridad que pueden surgir de las relaciones de fuerzas que intersectan el adentro con el afuera (del mundo), o el afuera con el adentro (de la mónada).

Ahora bien, el pasaje adentro/afuera queda abierto, pero el método para avanzar no es obvio. Es necesario ajustar las herramientas de exploración de la intuición desde una noción más sutil y más precisa del tiempo. Para ello, Deleuze (1996) traza el plano de conjunción entre la simultaneidad de flujos temporales "irreductible a, aunque indisociable de" la duración interna y el plano de composibilidad de cada multiplicidad. Pensando en ese plano, desde ese plano, solamente "en la perspectiva de un tiempo único pueden ser vivibles o vividos la multiplicidad de tiempos” (pp. 83 y ss.). Como vimos, la lección de Bergson es que monismo y pluralismo coinciden sin contradicción. Pero no es suficiente. Es necesario aclarar la diferencia implícita tanto en la noción de multiplicidad de tiempos como en el concepto de duración. Hay que volver, entonces, a Kant y a Bergson con un propósito más analítico que comprensivo, buscando en la temporalidad los candidatos al concepto de diferencia interna. Un precedente importante de la diferencia interna en Deleuze es la idea del tiempo como forma de la interioridad en Kant. Deleuze (1978/2008) remarca cómo la sucesión, la duración y la simultaneidad son modos que modulan la interioridad, y se interesa especialmente por la idea del tiempo como autoafección, sugiriendo que es Kant el primero en descubrir el tiempo como la forma bajo la cual "el sujeto se afecta a sí mismo" (p. 43). Si el espacio es la forma bajo la cual algo exterior me afecta, el tiempo es la forma bajo la cual yo me afecto a mí mismo. Kant, advierte Deleuze (2008), "ya no puede aceptar la idea leibniziana de que el tiempo es el orden de las sucesiones posibles y el espacio el orden de las coexistencias posibles" (p. 44). Por eso, sin renunciar a la complejidad mundo/mónada leibniziana,

de una cantidad intensiva cualquiera se hace en el instante [...]. Y otro rasgo de la intensidad: la multiplicidad contenida en una multiplicidad intensiva ya no remite a una sucesión de partes exteriores entre sí, sino a una aproximación variable al grado cero [...]. En otros términos, las reglas de la adición, de la sustracción, no valen para las cantidades intensivas. En la medida en que lo que está dado posee una cantidad intensiva, es decir un grado, lo capto dentro de una relación con su producción a partir de cero, o con su extinción” (pp. 55-56). 
Deleuze retoma la formulación tajante de la Crítica de la razón pura: así como el espacio es la forma de la exterioridad, es necesario que el tiempo sea la forma de la interioridad. Con la salvedad de que "forma de interioridad" entra en una zona de experimentación que pertenece tanto al sujeto como a la "exterioridad", o sea, a la multiplicidad relativista del espaciotiempo. Si bien tiene otros propósitos, Deleuze sigue a Bergson en su inteligencia del fenómeno a través de una suerte de introspección intuitiva de la memoria, buscando desde la consciencia el tiempo que escapa a la consciencia, o sea, sin presupuestos lógicos o conceptuales ${ }^{12}$.

El común denominador de esa coexistencia es el presente, en tanto contiene en sí mismo la infinitud del pasado y la infinitud del futuro. La idea del doble infinito ya está en Nietzsche, pero como aclara Deleuze (2002), al contraer los instantes sucesivos independientes, los unos en los otros, la síntesis "constituye el presente viviente. Y el tiempo se despliega en este presente” (p. 119). En definitiva, al presente pertenecen el pasado y el futuro. El pasado, en la medida en que "los instantes precedentes son retenidos en la contracción", y el futuro en cuanto "la espera es anticipación de esta misma contracción" (p. 119). El presente, afirma Deleuze, "no tiene por qué salir de sí para ir del pasado al futuro", sino que pasado y futuro constituyen dimensiones del presente (p. 120). Por su parte, el pasado puede ser pensado en bloque, como si todo el pasado -biológico, cósmico o reciente, incluso las promesas de futuro- estuviera activo en el presente: "el presente existe, pero solo el pasado insiste y proporciona el elemento en el cual el presente pasa y los presentes se interpenetran" (p. 140). La interferencia de pasado, presente y futuro libera la idea del tiempo de la consciencia y de su representación como un orden lineal "incondicionado", autodeterminado en función del pensamiento, y devela la indeterminación derivada de la potencia virtual de la memoria constitutiva del mundo y el pensamiento. Una forma de intuir esa

12 El propio Kant había hecho ya algunas incursiones reveladoras en la idea del tiempo como forma de la subjetividad y como forma de interioridad. De hecho, el tiempo interno está ligado en Kant a la duración. La pregunta por el tiempo de "mis representaciones" abre la pregunta por el papel de la memoria y la consciencia en esas representaciones. Tengo representaciones constantes respecto del presente, tengo consciencia espacial del presente, pero ¿cuántas y qué tipo de representaciones acuden al pensamiento sin que tenga que ver con la consciencia presente? La lectura de Deleuze induce a un orden de las representaciones que ya no es el orden de la consciencia presente que tengo de mis percepciones. 
relación entre pasado y presente, en su indiscernibilidad, es establecer el movimiento de repetición y diferencia en la materia: biológica, física, energética, cósmica, pero también en el sujeto, a nivel propioceptivo, afectivo, epistémico o espiritual. A partir de una pauta fundamental: si a la materia, que de por sí ya es diferencia, le corresponden en principio las determinaciones de la repetición, establecer la naturaleza de los procesos de diferenciación implica "mostrar que la diferencia es todavía una repetición y la repetición ya es una diferencia” (p. 127).

Lo más importante de ese double bind es haber descubierto cómo la diferencia habita la repetición: "entre una repetición que no deja de deshacerse en sí y una repetición que se despliega y se conserva para nosotros en el espacio de la representación", sucede la diferencia, que es el para-sí de la repetición (Deleuze, 2002, p. 127). Si la diferencia se halla entre dos repeticiones, es el tiempo mismo el que produce la diferencia interna. Significa que la repetición opera "como el diferenciante de la diferencia” y abre el pasaje de la representación de las diferencias exteriores a la diferencia interna (p. 128). En lugar de hacer cortes en bloques temporales -cuánto nos demoramos de un lugar a otro, cuánto una planta en crecer, los períodos de la vida para hacer ciertas cosas, las edades de los estratos geológicos-, en lugar del cálculo, se trata de trabajar con la experiencia, de seguir los flujos del tiempo en su propia duración. Mientras la diferencia evidente, visible, es la diferencia de naturaleza, la duración se convierte en el concepto propiamente diferenciador. Lo que parece una actitud anticonceptual y anticientífica es realmente lo contrario. Es propio del concepto de diferencia interna acceder $a s i$ mismo a través de la intuición, la propiocepción y la autoobservación. Solo de ese modo la duración se revela en la diferencia natural del sujeto como elemento diferencial privilegiado. Al precisar el elemento de diferenciación (différenciation) interna, las diferencias de naturaleza se muestran como casos de la diferenciación (différentiation): "la diferenciación (différentiation) reenvía a la determinación por relaciones diferenciales del contenido virtual de la idea, y la diferenciación (différenciation) remite a la actualización de esa virtualidad en las especies y las partes distinguidas como correspondientes a los casos de solución del problema" (Alliez, 1998, p. 253). Diferenciamos unas cosas de otras, las describimos, las enlazamos causalmente, pero la pregunta filosófica es por la esencia de la diferencia que se ocupa de la diferencia misma en su movimiento de diferenciación (différentiation). Insistiendo en la duración, Deleuze problematiza toda ontología desde 
el esquema diferencia/repetición y convierte la filosofía en una experimentación de la frontera entre diferencia natural y naturaleza de la diferencia. El resultado es una multiplicidad interna que revela el acontecimiento y la producción de lo nuevo por generación ideal de discontinuidades. En su apropiación experimental de Bergson, Deleuze entiende que la consciencia se ha convertido en el laboratorio del filósofo en donde puede registrar la heterogeneidad de tiempos que no pasan por la consciencia. Esa paradoja, además de las discusiones típicas sobre la (im)posible consciencia del inconsciente en psicoanálisis, supone otra según la cual la idea kantiana del tiempo como forma de la interioridad del sujeto debe aceptar una suerte de anterioridad de los flujos de materia y percepción que corresponden a la pura duración, ajenos por tanto al concepto y a la consciencia.

A continuación, siguiendo simultáneamente al Husserl de la percepción, lo presignificativo y la noesis como actividad sin objeto, $y$ al Leibniz de la micropercepción, la síntesis topológica y el análisis del predicado sin sujeto, Deleuze abre la investigación en dos direcciones: la síntesis pasiva y la síntesis activa. La síntesis pasiva se ocupa de las continuidades implícitas en "nuestros miles de hábitos componentes, formando en nosotros otros tantos yo supersticiosos y contemplativos, y otras tantas pretensiones y satisfacciones" (Deleuze, 2002, p. 125). Dado que la contemplación no surge de la acción, hay una tendencia a olvidarla como un fondo inaudible, irrepresentable, con lo cual los procesos de acción y reacción parecen ajenos a la repetición. Por el contrario, Deleuze pone en primer plano la diferencia que surge en la contemplación de esa multiplicidad de estados larvarios. De repente, por un cambio de perspectiva, se abre la dimensión ontológica de una multiplicidad de "pequeños yo que contemplan y que vuelven posibles la acción y el sujeto activo” (p. 125). En un lenguaje más profuso, incisivo y elocuente, esa es la lección de Beckett: la proliferación de "testigos que contemplan en nosotros" y a través de los cuales el sujeto "larvario" dice yo (p. 125). Lo que resulta de allí es el campo de las síntesis pasivas que nos constituyen en un plano intratemporal previo a cualquier síntesis activa. Esa es, además, la primera deducción intuitiva del hábito como "síntesis originaria del tiempo", que constituye la experiencia del presente viviente, la vida del presente que pasa (p. 133).

La síntesis activa, por su parte, contiene dos aspectos correlativos: reproducción y reflexión, rememoración y reconocimiento, memoria y entendimiento. De esa correlación se deducen la Memoria como síntesis fundamental del 
tiempo, "que constituye el ser del pasado", y la síntesis de la memoria activada por la Representación bajo el doble aspecto de "reproducción del antiguo presente y reflexión del actual” (Deleuze, 2002, p. 134). La síntesis activa de la memoria constituye el pasado puro en el tiempo, y hace del antiguo presente, y del actual, "los dos elementos asimétricos del pasado" (p. 134). En esa asimetría, Deleuze parece haber descubierto la emergencia y la complejidad constitutiva del tiempo como tal. No se trata simplemente de que, ante un nuevo presente, el presente ya pasado se instale en la memoria como un "algo" irreductible. El pasado es impuro, está irremediablemente contaminado de presente. Si el pasado esperase un nuevo presente para constituirse como pasado, dice Deleuze, "el antiguo presente no podría pasar nunca ni el nuevo llegar” (p. 134). En definitiva, un presente nunca pasaría si no fuera al mismo tiempo tanto pasado como presente. De esa coincidencia depende su profunda asimetría. Y de esa paradoja, según la cual el pasado es contemporáneo del presente ya sido, se desprende una nueva paradoja: la de la coexistencia. Sin desatar las paradojas en cascada que provoca en la imaginación, Deleuze lleva la deducción hasta su cifra lógica posible: "si cada pasado es contemporáneo del presente que ha sido, todo el pasado coexiste con el nuevo presente con respecto al cual ahora es pasado" (2002, p. 135). Por su pertinencia para comprender la dinámica molecular de la diferenciación interna, refiero dos variaciones deleuzianas de la ecuación que articula el tiempo que adviene y del pasado en continua actualización: (i) "el pasado no hace pasar uno de los presentes sin hacer advenir el otro, pero él no pasa ni adviene. Por ese motivo, lejos de ser una dimensión del tiempo, es la síntesis del tiempo entero cuyo presente y futuro no son más que dimensiones" (Deleuze, 2002, p. 136); (ii) "será necesario entonces que todo el pasado coexista consigo mismo, en diversos grados de distensión y de contracción" (p. 137). En el límite de la ecuación, se trata de confirmar la idea bergsoniana según la cual cada presente actual no es más que el pasado entero en su estado más contraído. Lo que vivimos empíricamente como una sucesión de presentes diferentes desde el punto de vista de la síntesis activa es, también, "la coexistencia siempre creciente de los niveles del pasado en la síntesis pasiva" (p. 138).

Esa ecuación es la clave para trabajar en una ontología del presente que insiste en la diferencia interna, al tiempo que afianza el concepto de duración como "lo que difiere de sí mismo". Mientras que la materia se diferencia en la definición 
de sus atributos identitarios, y se repite bajo las distintas formas de la representación, la duración entraña una diferencia consigo misma que no pasa por la representación. Ahora bien, dado que para Deleuze, "aquello que difiere de sí mismo es inmediatamente la unidad de la substancia y del sujeto” (2005a, p. 52), vuelve la pregunta acerca de si finalmente el método tiene un punto ciego radicalmente antropocéntrico. Con esa sospecha quisiera abordar una tercera síntesis, que podríamos llamar sintesis vital, desde la cual es plausible tematizar las diferencias inscritas en el desarrollo evolutivo de los seres vivos y que, en el fondo, pone en entredicho la división tajante entre materia y vida. Para ello, es necesario retomar la idea del tiempo como un mixto de espacio y duración, en bergsoniano: concebir el espacio como un mixto de materia y memoria, de materia y duración. Deleuze descubre que Bergson ofrece una alternativa a la pura cuantificación del movimiento en el abordaje del tiempo, y esa aproximación le resulta especialmente productiva para analizar la repetición. Para empezar, en la superficie del comportamiento, la intuición confirma la continuidad que conlleva el hábito y las dificultades para establecer la (in)consciencia de un tipo de duración evidente. En esa exploración, Deleuze y Bergson comparten un empirismo común que tiene como requisito la realidad siempre emergente de la diferencia. Esa emergencia se explica por la inserción de la duración en la materia: "la duración se divide según los obstáculos que encuentra en la materia, según la materialidad que atraviesa, según el género de extensión que contrae" (Deleuze, 2002, p. 99). A partir de allí, todo sucede "como si la Vida se confundiera con el movimiento mismo de la diferenciación en series ramificadas" (p. 99). Por su parte, Deleuze deriva de allí una potencia de integración que tiene su concrescencia en la totalidad viviente, entendida como la continuidad heterogénea de interpenetración recíproca entre lo vivo y lo no vivo que, en la lectura de Alliez, reenvía al bergsonismo "a su centro virtual de expresión" (1998, p. 248). La duración se diferencia en sí misma por una "fuerza interna y explosiva" que no deja de afirmarse y prolongarse en las más diversas series y ramificaciones referidas por el evolucionismo. En esa perspectiva, la unidad y la multiplicidad no parecen tener una jerarquía explicativa. Se entiende que la diferenciación es una actualización que supone una unidad, "una totalidad primordial y virtual que se disocia según las líneas de diferenciación” (Deleuze, 2002, p. 99). Los dos planos de la diferencia tienden a (con)fundirse en la repetición: la duración se llama vida precisamente 
cuando se muestra en movimiento. Digamos que es la vida misma como un todo, antes de su concepto, la que se divide en planta y animal, en instinto e inteligencia, arrastrando las ramificaciones de su división y la expresión vital de cada una de esas singularidades "como una nebulosidad que la acompaña testimoniando su origen indiviso" (p. 99). Pero al final, la Idea-problema de la diferencia interna no solo afecta el principio causal externo sino que deja varios interrogantes sobre el impacto de la imbricación entre materia y duración en la deconstrucción de la diferencia entre interior y exterior.

La búsqueda de una cuarta síntesis explora algunas de esas preguntas. Siguiendo a Leibniz, la estrategia de Deleuze será llevar la duración bergsoniana a una formulación topológica. Para ello, esboza los parámetros de una sintesis extensiva entendida como una suerte de cartografía intensiva del plano de inmanencia, el cual puede ser compartido tanto por los seres vivos, incluidos los humanos, como por la materia, la energía y las fuerzas en general. El término sintesis se entiende aquí como la explanación del proceso de diferenciación de las series sobre un plano específico, tal como sucede con las topologías que despliega en "Síntesis ideal de la diferencia" (cap. 4 de Diferencia y repetición). Dicho de otra manera, la unidad que ofrece la vida en su proceso evolutivo es apenas la expresión más evidente de la duración que está por investigar en el resto de la naturaleza, teniendo en mente la (in)diferenciación de la oposición vivo/no-vivo como pregunta o "cabeza buscadora". Al trabajar un poco más allá o más acá de lo vivo, el concepto de duración redefine la continuidad que está implícita en esa des-diferenciación ${ }^{13}$. O mejor, es plausible extender el concepto de duración a todo tipo de campo espaciotemporal en forma de fuerzas, atributos y propiedades químicas de la materia que exceden la percepción y la medida humanas. La ilimitación en el espacio se corresponde con la inconmesurabilidad en el tiempo. Para comprenderlo tendríamos que, como ya lo estamos haciendo, utilizar prótesis de visión y memorias externas que ya consideramos como propias por un

13 Si todo proceso de actualización y de individuación es en cierta medida un momento discreto en la materia, ¿ cómo registrar la (dis)continuidad? ¿Es representable lo continuo? Pensemos en las grandes religiones. Las podemos representar, nombrar, clasificar en su discontinuidad, pero la pregunta sobre la continuidad es cómo fluye internamente una forma religiosa específica. La continuidad ayuda a entender el concepto de duración sin que este se reduzca a aquella. 
sentido extendido de humanidad. De ahí la necesidad de establecer una sintesiscontinuum para la cual es insuficiente acudir a la memoria de los seres vivos o a nuestra propia memoria, aunque no deje de estar presente en ella la certeza cósmica de que tanto las formas vivas primarias, como las plantas, los animales y los humanos somos, básicamente, resultado de la relación entre materia y memoria. A partir de ese "dato", en lugar de conducir la explicación hacia el determinismo, Deleuze (2005a) encuentra en Bergson argumentos para postular esta última versión de la diferencia interna como la indeterminación misma y no como una determinación intrínseca. Habría que establecer en cada caso la forma en que se hacen compatibles la continuidad de la duración indiferenciada con la indeterminación, pero ya ha quedado establecida por Bergson en el carácter imprevisible de las formas vivas. Esa comprobación inicial lleva a Deleuze a corroborar la hipótesis según la cual "para Bergson lo imprevisible, lo indeterminado no es lo accidental sino, al contrario, lo esencial, la negación del accidente” (p. 55). En realidad, se trata de un aspecto de la diferencia todavía en suspenso, que se desprende de los accidentes y del azar, pero que estaba ya en la adopción deleuziana de "la contingencia irreductible" de Hume como una condición de la reconstrucción racional de los hechos, "sin que esa contingencia implique una negación de las causas” (Danowski, 1998, p. 204). En bergsoniano, la relación causa-efecto puede ser puesta en segundo plano para considerar las relaciones de fuerzas desde la perspectiva de la relación que las fuerzas, los objetos, los fenómenos, los individuos desarrollan consigo mismos internamente para llegar a ser lo que son.

¿Es lo indemostrable, lo contingente, lo indeterminable una entrada deleuziana en la metafísica de la mano de la física molecular? ¿Es más prudente esperar a que la ciencia resuelva las preguntas que la filosofía no termina de formular por su tendencia a la autorreferencialidad conceptual? ¿Puede acaso el propio Deleuze detener las líneas de fuga que no cesan de prolongar su filosofía hacia el futuro? No lo sé. Por ahora, prefiero insistir en la claridad con la que Deleuze lograr abrir el arco y multiplicar las máscaras que acompañan el péndulo incesante entre interioridad y exterioridad, ocupado en la filigrana que teje la diferenciacion (différentiation) interna en la urdimbre ontológica de la diferenciación (différenciation). De hecho, podría estar satisfecho por haber suspendido el juicio sobre la diferenciación externa como un efecto de lo visible, y haber dirigido el foco hacia la ontología de lo imperceptible. Contra toda lógica, lo 
que ha hecho es construir topo-lógicamente una diferencia que recorre la cinta de Mœbius entre tres interioridades que no terminan de encontrar un pliegue definido de conjunción: la interioridad del sujeto, la interioridad de lo vivo y la interioridad de la materia inorgánica. Podemos aceptar una constante diferenciación en la motilidad del individuo humano y de los seres vivos, pero resulta extraño concebirla en el campo de lo que llamamos materia inanimada sin que la interioridad se convierta en un fantasma de la voluntad de poder. Para ello, habría que deconstruir las oposiciones habituales entre materia y energía, entre objeto y relaciones de fuerza, entre ánthrôpos y máquina, entre cálculo y duración.

Quizás no sea necesario ir tan lejos. Al fin y al cabo, todo estaba en Bergson, al menos desde el momento en que se propone explorar la relación entre memoria y materia; y en lugar de oponer radicalmente la memoria interior, personal, diversa, a la memoria de la diversidad exterior, a toda materialidad, se propone concebirlas como un continuum del espectro infinito de la duración. Así como justificamos cada proposición por su referente, en adelante, en la filosofía de la diferencia, no hay descripción de lo ente sino descripciones de las intensidades que afectan la duración de lo ente. La duración, el flujo, la temporalidad, la medición del tiempo, la relación de esa multiplicidad de tiempos en el interior de la materia, son tan relevantes como los que afectan al propio individuo en su experiencia interior. Sea una célula, un organismo o una estrella, ahora sabemos que la diferencia natural es indisociable de la diferenciación temporal que la singulariza internamente. En hegeliano, la experiencia cuantificada es el primer paso para conceptualizarla en su propio en sí y hacerla comprensible para nosotros. Damos por cierto que en la materia inorgánica hay un grado de diferenciación menor que en los seres vivos (Deleuze, 1996, p. 138). De esa certeza deducimos que la repetición en la materia tiende a cero, pero al poner en primer plano el concepto de duración como una síntesis topológica de la totalidad de lo ente, más que repetición, lo que tenemos es la memoria extendida de la materia. La materia comporta su propia memoria en un modo que nos impide diferenciar inmediatamente la virtualidad (de la memoria) de la actualización (de la materia). ${ }^{14}$

14 Esta es la posición general de Bergson sobre el problema: "La verdad es que habría un medio, y solo uno, de refutar el materialismo: sería establecer que la materia es absolutamente como parece ser. En ese caso se eliminaría de la materia toda virtualidad, toda potencia escondida, y los fenómenos 
Pero eso no impide que podamos trasladar a la matriz deleuziana virtual/ actual las conclusiones que Bergson intentaba abstraer en términos de materia y espíritu. En adelante, para Deleuze, virtual es el concepto que aclara todos los conceptos del propio Bergson y abre un ámbito para la filosofía de la ciencia distinto al de la ley natural. $\mathrm{O}$ mejor, de la misma manera que la repetición en su exterioridad parece obedecer a la relación causa-efecto, en su interioridad potencia la experiencia del tiempo como un diferencial irreductible a la causalidad. De repente, necesidad e indeterminación son compatibles por arte de la virtualidad, que sirve de sombra activa al acontecimiento. Lo virtual puede ser o no ser, pero no puede dejar de actualizarse; de otra manera sería irreconocible como virtual. Es en la actualidad del acontecimiento donde vemos retrospectivamente la virtualidad que lo ha hecho posible. Sintetizando: la virtualidad es indeterminable, aunque se determine en su actualización.

Con ese argumento, Deleuze se anima a corroborar la tesis de Nietzsche que descarta el finalismo como ley general del universo, y postula la necesidad del eterno retorno en clave de repetición. Sin embargo, la tentación de pasar del lenguaje de la necesidad al de la ley es constante. Al fin y al cabo, tanto el movimiento circular cósmico como la pluralidad de fuerzas no son formaciones posteriores sino que tienen la impronta de leyes primordiales. Para conjurar esa tentación, el postulado nietzscheano que distingue ley y necesidad sigue siendo una opción y una provocación al pensamiento: "podemos creer que una absoluta necesidad reina sobre todas las cosas, pero guardémonos de afirmar que una ley, cualquiera que sea, domina en el universo como una propiedad eterna del mismo" (Nietzsche, 1932, p. 8).

Puesto en los términos iniciales, esa advertencia afecta el principio lógico por el cual seguimos buscando en la materia, en lo vivo o en los sujetos el criterio de un principium individuationis que sería su propia ley de reconocimiento y diferenciación. $\mathrm{Al}$ abrir el interior de la diferencia a los diversos procesos de individuación del sujeto, de la materia o de los seres vivos, en una topología de

del espíritu tendrían una realidad independiente. Por eso mismo habría que dejar a la materia esas cualidades que materialistas y espiritualistas acuerdan en apartarle, estos para hacer de ellas representaciones del espíritu, aquellos por no ver en ellas más que el revestimiento accidental de la extensión” (2006, p. 84). 
continuo cruce e intersección, Deleuze muestra cómo y por qué la conceptualización de la diferencia interna es indiscernible de las fuerzas que la atraviesan y de la duración que le da su propia consistencia. La paradoja es que, justo cuando creíamos haber cumplido con la re-construcción conceptual prometida, se hace ineludible una pregunta que hace eco en su obra posterior: ¿por qué el propio Deleuze nunca volvió a utilizar la noción de diferencia interna, ni a predicar la interioridad de ningún otro concepto?

\section{En el umbral de las mutaciones}

La sospecha Que guía eSte apartado es que el concepto de diferencia interna pierde vigencia después de haber hecho su trabajo en Diferencia y repetición. Es como si "interna" hubiera servido de acicate para explorar el movimiento propio de la diferencia y la repetición hasta convertirlos en una suerte de esquematismo ontológico y temporal ineludible, aunque en sentido estricto no tengan como resultado algo que se pueda demostrar o refutar, sino experimentar. La experimentación, sea científica, conceptual o existencial, se vuelve lo propio de la filosofía de la diferencia. En esa condición, es plausible restituir el eterno retorno, no como una ley deficiente y enigmática, o como la eterna confirmación ilusoria de la vuelta de lo Mismo, sino como un movimiento dotado de la fuerza para seleccionar, expulsar, crear, destruir, producir la diferencia.

$\mathrm{Al}$ pensamiento de esa producción de la diferencia, a su conceptualización, es a lo que Deleuze muy pronto dejará de llamar diferencia interna. La obra posterior, desde Lógica del sentido (1969/1989a), consistirá en encontrar nuevos conceptos, fronteras disciplinares, protocolos de experimentación, lenguajes y formas de expresión para lo que hasta ahora eran variables autopoiéticas, afirmaciones de la multiplicidad, proliferación de series temporales o síntesis -pasivas, activas, vivientes, topológicas- sobre el plano de inmanencia donde acontece la diferenciación. La idea es recorrer algunos de esos pasos con el fin de mostrar cómo la constitución del concepto de diferencia interna, al final, deriva en su disolución. La justificación de esa interpretación remite a las obras posteriores, pero se sustenta en una suerte de hipótesis retroactiva que, a mi juicio, opera como vector constructivo desde su primera obra, Empirismo y subjetividad (1952/1977). En este texto se vislumbran ya las pautas del empirismo superior: 
observación interna, multiplicidad en lugar de "objeto", alteración de la secuencia causa/efecto, disolución del yo; y una primera y definitiva certeza epistémica, según la cual la repetición "vestida" sucede en el sujeto y, por tanto, en los lenguajes que le sirven de plano de expresión. En su esencia, dirá Deleuze (2002), la repetición es "simbólica, espiritual, intersubjetiva o monadológica", lo cual no significa que entre necesariamente en el campo de la consciencia (p. 168).

Una segunda entrada remite a Bergson, de cuya lectura se sigue la formulación explícita del concepto de diferencia interna en cuestión. El primer efecto del predicado "interno" es horadar el concepto en su diferenciación (différenciation) ontológica, identitaria, desde dentro. El segundo, es exponer la diferencia y, en sentido estricto, la diferenciación (différentiation) al movimiento pendular entre diferencia y repetición. Al radicalizar la diferentiación (différentiation) temporal, Deleuze inutiliza una solución dialéctica que pudiera conciliar la diferencia ontológica con la diferencia interna, como si se tratara de facetas del mismo concepto. Lo que se plantea es que no hay un concepto de la diferencia, es decir, que la repetición sucede sin concepto, se produce sin conceptualización. Pero ya se vislumbran, en el intento de conceptualizar la interioridad de la diferencia, transformaciones materiales, temporales, imperceptibles que señalan los límites de la representación. El predicado "interno" provoca la tematización de su contrario, y se inscribe en una serie de paradojas que replican el axioma de una conceptualización unívoca del Ser y del Pensar como divisa del empirismo superior.

La filosofía no se había ocupado de la repetición más que como un problema derivado del tiempo, que hacía parte -irrelevante- de los procesos de generalización y universalización. A partir de ahora, en bergsoniano, la repetición expresa la memoria de la materia. Y esa es justamente la razón por la que entraña la diferentiación (différentiation). La deducción parecería metafísica, si no fuera tan radicalmente materialista el enunciado que implica a la memoria en la multiplicidad de atributos de la materia que coinciden en tal o cual modo singular de individuación. El pájaro, el cristal, la piedra, el flujo de agua o el nevado comportan su propia duración material, pero también la temporalidad de su composición con otras materias, la de las fuerzas que lo afectan, la de su intensidad. Como bien lo describe Sauvarnagues (2006), Deleuze aplica a la haecceidad -una forma de incorporar en la cosa el plus de su singularidad, de su ser así y no de otra manera- las nociones de latitud y longitud: mientras "la longitud refiere a la 
composición de partes", la latitud indica "la variación de potencia”. Bajo esa premisa, todo individuo consiste en "una relación (fluctuante) entre una extensión de partes y una intensidad de potencia" que nos permite considerar la singularidad de las diferentes formas de individuación como "resultado de un diagrama de fuerzas ejercidas efectivamente" sobre ellas (pp. 119-120).

En síntesis, así como Deleuze trata de describir el tiempo de la diferenciación (différentiation), así mismo el "objeto" ya no es simple materia, sino tiempo, intensidad y diferenciación. En Diferencia y repetición se trata de descubrir las disposiciones metafísicas y epistémicas para lograrlo, y la primera es dejar en segundo plano las cantidades extensivas, los movimientos locales y las cualidades físicas, para entrar en el dominio de las cantidades intensivas. El interés de Nietzsche por las intensidades puras le ofrece a Deleuze un (no $e l$ ) contenido privilegiado para el concepto de diferencia interna. Pero pronto el predicado contenido desborda el sujeto que lo contiene. Dado el compromiso con la interioridad del tiempo, se establece una colusión de interioridades en la medida en que la forma de intensidad, que sería el quantum específico de la materia implicada en $x$ complejo de fuerzas, compite ahora con la forma de interioridad del tiempo, que no solo constituye la subjetividad (Kant), sino el acceso a la duración de la materia en su multiplicidad.

La idea de Deleuze (2002) de que toda diferencia es, en última instancia, "intrínseca y conceptual", empieza a resultar insuficiente. Con el cúmulo de conceptos que se han ido acoplando al campo problemático, Deleuze retoma la idea según la cual, "hay diferencias internas que dramatizan una idea antes de representar a un objeto” (p. 57). Pero, en lugar de buscar la completud husserliana del significado que pudiera integrar la exterioridad de la representación del objeto con la interioridad de la diferencia, busca elementos para expresar esa oposición como un ejercicio de dramatización del pensamiento. Ya en su primera lectura de Bergson, evocando la complejidad de la vida psíquica, Deleuze (2005a) resalta la idea bergsoniana según la cual "el matiz es la esencia” (p. 50). El método de dramatización lo lleva a contrastar completud semántica (Husserl) y matiz diferenciador (Bergson) como una elección epistémica que lo va a caracterizar en adelante como el filósofo de la diferencia. Renunciar categóricamente a las articulaciones de lo real que nos ofrecen las diferencias de naturaleza en la búsqueda del significado es compensado, sin embargo, con la búsqueda sistemática de la "cosa misma" como diferencia interna. La razón, dice Deleuze, es que la 
diferencia expresa los procesos de individuación, y en la descripción constitutiva de esos procesos el verdadero concepto debe llegar hasta la cosa singular.

Dramatizando al propio Deleuze, diríamos que, así como el vitalismo de Bergson modula intuitivamente el formalismo de Kant respecto de la interioridad del tiempo, así también su inscripción en el empirismo que va de Hume a Nietzsche le sirve para resistirse a adoptar el espiritualismo que proyecta el vitalismo de Bergson. En el plano de inmanencia bergsoniano conviven la moral y el yo con el cuerpo, el sentimiento, la autoobservación y la emoción, bajo la égida espiritual del élan vital. Deleuze parece inmerso en la doctrina del vitalismo bergsoniano, pero entretanto ha descubierto dos estrategias que luego llamaría líneas de fuga. La primera, remitir las consecuencias del vitalismo a la noción de virtual, despojando a Bergson de la organicidad que envuelve toda su filosofía. La segunda, en lugar de otorgarle un impulso vital a todo lo vivo "por derecho", distribuir las singularidades intensas en la extensión topológica que configura el plano de inmanencia. Así, lo que parecía un privilegio de lo humano se extiende a los procesos de individuación más diversos, como si todos ellos participaran del invento bergsioniano del cono invertido, instalados en el cual, de una parte, la presencia del "presente insiste en el extremo puntual del cono de la memoria", mientras de la otra, la virtualidad de la memoria "en su expansión se hace una con la materia” (Deleuze, 1996, p. 105; énfasis añadido). Al apropiarse del método de la intuición temporal en perspectiva nietzscheana, Deleuze avanza en la deconstrucción de la interioridad cristiana-representacional, y lo dispone en función de la experimentación spinozista con las potencias del cuerpo y, en sentido estricto, con la voluntad de poder.

La tarea nietzscheana de la transvaloración supone una experimentación y un lenguaje distinto para la relación entre exterioridad e interioridad. El efecto cognitivo y epistémico que supone mantener activa la frontera adentro/afuera es el de poner en acción la idea nietzscheana de la indeterminación de mi naturaleza en consonancia con la indeterminabilidad de la naturaleza. El grado de variación impredecible que supone el juego relacional de las diferencias externas adquiere una correspondencia interna que apenas empezamos a intuir en términos bio-químico-neuro-antropo-temporales. La fijeza del individuo en su contracción puntual, en su movimiento por el vector del presente, es indisociable de los cambios, los desplazamientos, las interferencias a la que está sometida la 
materia, la cual no deja de "extenderse haciendo de la distensión su movimiento esencial” (Deleuze, 1996, p. 105). No sé si Deleuze tenía presente en esta afirmación la expansión continua del universo desde el Big Bang, pero es evidente que los datos y las proyecciones físicas exigen examinar las tesis cosmológicas de Nietzsche. Podríamos seguir hablando de un universo sin finalidad, pero no se puede repetir la idea del eterno retorno como si se tratara de un juego inacabable entre infinitos sustentado en su pura posibilidad lógica, ni se puede ya negar la idea de un fin en el tiempo para el universo conocido.

Por lo demás, el movimiento de contracción/distensión aplica en varias escalas y diversos grados de heterogeneidad: va de lo cósmico a lo personal, de lo vivo a lo inorgánico, del sistema solar a la galaxia, de la galaxia que se contrae a la expansión de otras galaxias, ofreciendo una infinidad de perspectivas composibles. Cada una de esas perspectivas puede ser leída al mismo tiempo como principio monádico, como valoración y como mundo posible, y anuncia la exploración minuciosa de la frontera adentro/afuera sobre la que Deleuze va a insistir hasta el final de su vida. La diferencia interna opera como un espacio transicional de experimentación, en la búsqueda de un plano de inmanencia cuya característica fundamental sea la indiscernibilidad entre interioridad y exterioridad, a la cual Deleuze dedicó los dos tomos de Capitalismo y esquizofrenia (Deleuze \& Guattari, 1972/1985 y 1980/1988) ${ }^{15}$, la Lógica de la sensación (1984/2005c) y El pliegue (1988/1989b), el libro dedicado a Leibniz. En ese horizonte, la pertinencia de las duplas adentro/afuera, diferencia/repetición, actual/virtual, contracción/distensión no es puramente vital, epistémica o temporal, sino que apunta a trazar otra topología del plano de inmanencia, entendido como imagen del pensamiento.

Para ello, era necesario deconstruir la oposición adentro/afuera. El punto es que, donde interna normalmente denotaba el vacío que suponemos en la interioridad, ahora es el vector de concurrencia de las relaciones de fuerza inscritas en la dinámica diferencia/repetición. En nietzscheano, se reafirma el eterno

15 En El Anti Edipo, el concepto de máquina social se construye con esa duplicidad entre interior/ exterior, de modo que la descripción socio-técnica de las máquinas resulta indiscernible de la heterogeneidad de flujos que comporta el complejo de Quantum (fuerzas), Numen (energía de distribución) y Voluptas (deseo), considerado como la máquina abstracta en donde se inscribe la máquina social (Deleuze \& Guattari, 1985, pp. 25 ss). 
retorno como algo que "se dice solamente del devenir, de lo múltiple", y permite entender por qué un mundo al que se le ha sustraído el ser, la unidad, la identidad, en pro de una misteriosa diferencia interior, tiene en compensación la multiplicidad como "la única identidad de lo que difiere" y el retorno como "el único 'ser' del devenir" (Deleuze, 1986, p. 163). Sin embargo, hay que recordar la precisión con que Deleuze opera el ajuste bergsoniano de la física nietzscheana. El pasado y el futuro nietzscheanos se convierten en infinitos que varían desde el presente que los convoca. Parece sencillo: el presente se compone de las virtualidades del pasado y las posibilidades del futuro. La dificultad es pensar el enunciado de eternidad como aplicable a pasado y futuro sin naturalizar lo trascendental. Bergson lleva esa conjunción de eternidades al plano de lo espiritual. Deleuze sustituye lo espiritual por lo virtual en un gesto de materialismo radical, de modo que lo virtual pueda servir de referente temporal a todo tipo de interioridad -la cual, a esta altura, parece ya indistinguible de la duración-.

Claude Smith (2015) ha sabido ubicar este desplazamiento en el discurso de la época, señalando cómo Deleuze critica la atemporalidad de la estructura y la empieza a concebir como una "temporalidad virtual" que sería inexacto oponer al acontecimiento, ya que ella "tiene toda una historia que le es interior" (p. 42) y a través de la cual sucede el proceso de engendramiento del sentido. En adelante, la determinación cuasi-causal de lo virtual (término recurrente en Lógica del sentido) podrá ser predicada de toda materialidad, sea cual sea su forma de interioridad. De repente, los conceptos de Bergson son resignificados desde una concepción no exclusivamente perceptible de la materia, y el tiempo adquiere los visos de una extraña materialidad, igual que fuerzas como la gravedad, la luz o la energía. Pero lo que parece composible en términos temporales no funciona, o por lo menos no simétricamente, en el caso de la interioridad. Las distintas formas de interioridad son inconmensurables, aun en el caso de que la duración sirva de plano de coincidencia entre el plano de inmanencia (de la materia en su pluralismo) y de las temporalidades (en su multiplicidad). La primera opción de Deleuze es retomar la intuición intelectual de Bergson para acceder a la intelección de la diferencia interna, entendida como el pasadizo espaciotemporal entre los dos planos, de modo que la duración entendida como una y múltiple pueda servir, en su indiferencia, para dar cuenta de la experiencia interior del sujeto $y$ también de la interioridad de la materia en su diversidad. 
En la doctrina de Nietzsche todo ello evocaba el caos, con elementos tomados de la física, la astronomía y la pura existencia. Deleuze mantiene así la divisa de un empirismo superior basado en la experiencia, pero queda sin resolver plenamente la duración como un concepto inscrito en la interioridad del objeto. El recorrido que va de la sintesis-continuum al texto sobre Leibniz es un intento notable por dotar al problema de una cierta de forma de totalidad. En Diferencia y repetición (2002) ya se adivina la consistencia que adquiere el proyecto desde el spatium, entendido como lo que no tiene "ninguna realidad física", aunque a partir de él se establezca "el orden de los puntos de vista coexistentes" (p. 334). Una lectura transversal demostraría que Deleuze tiende a reemplazar "interioridad" por "emplazamiento" y este a su vez por "punto de vista", con lo cual spatium se puede definir como la multiplicidad de puntos de vista que constituyen un determinado mundo (posible). El plano matemático leibniziano así reconstruido parece disponible para incorporar los conceptos nietzscheanos.

En efecto, es en la reformulación del eterno retorno donde Deleuze (2002) parece encontrar una solución metódica que actualiza los efectos de "la muerte de Dios" y "la disolución del yo" en la producción de pensamiento (p. 35). A la voluntad de desdeificación del ente en su totalidad, como dice Heidegger, se suma la excentricidad del interior del sujeto, ahora expuesto a todo tipo de afecciones, fuerzas y temporalidades. A riesgo de convertirlo en cantinela, Deleuze no deja de invocar lo múltiple en cuanto múltiple como la única identidad de lo que difiere; y la repetición y la diferencia como único ser del devenir. Si el eterno retorno se dice solamente del devenir, en el borde de la tautología, el devenir es lo único que podemos afirmar del mundo de las diferencias en su multiplicidad. Por tanto, a las máscaras y agenciamientos que ocupan la interioridad destituida del sujeto les corresponde devenir en un mundo sin finalidad y sin intencionalidad. Lo que no impide afirmar todo lo contrario. Esto es, la voluntad de poder como el querer "más alto" y el pensamiento del eterno retorno como un principio selectivo "que hace del querer una creación". No se trata ya de un pensamiento selectivo, repite Deleuze (1986), "sino del ser selectivo porque el eterno retorno es el ser, y el ser es selección” (p. 102).

Los enunciados más polémicos de la "doctrina" adquieren así su propia actualidad. Podemos aceptar el devenir, entonces, como un principio ilimitado para mundos limitados y el mundo "nuestro" como carente de regulación intencional, 
sin que se pueda decir que carece de necesidad; más aún, sin poder refutar la idea de que finalmente el caos del mundo es, en sí mismo, necesidad. Pero en lugar de intentar una metafísica del eterno retorno, Deleuze avanza en su propia filosofía de modo tal que estos principios son recursos para salir del antropomorfismo y el régimen de representación de la filosofía moderna hacia la semiotización de las fuerzas, las intensidades, el sentido, como si allí estuviera la clave expresiva de una ontología de lo múltiple. Corresponde entonces a la filosofía futura, que quizás sea la nuestra, ocuparse del caosmos, de "presentes sucesivos, vínculos no localizables, acciones a distancia, sistemas de reanudaciones, resonancias y de ecos, azares y objetivos, señales y signos, roles que trascienden las situaciones espaciales y las sucesiones temporales" (Deleuze, 2002, p. 139).

Lo cierto es que después de Diferencia y repetición, Deleuze no cesó de crear/ pensar, haciendo de la filosofía un arte en constante experimentación y diferenciación (de sí misma). En todos esos nuevos conceptos, modos de vida y planos de inmanencia es notoria la ausencia del predicado "interno" y su relevo por la mezcla, la conjunción de lo divergente, la relación sin relación, la paradoja constitutiva, en fin, el in-between como matriz de toda operación lógica, descriptiva, epistémica o intuitiva capaz de habilitar la génesis de multiplicidades sobre el plano de inmanencia donde acontece la diferencia. Al final, inspirados en Maurice Blanchot, Deleuze y Guattari (1991/1993) develan la fórmula matriz de esa topología internal que vino a reemplazar la diferencia interna:

Diríase que EL plano de inmanencia es a la vez lo que tiene que ser pensado y lo que no puede ser pensado [...] Es lo más íntimo dentro del pensamiento y, no obstante, el afuera absoluto. Un afuera más lejano que cualquier mundo exterior, porque es un adentro más profundo que cualquier mundo interior (p. 62).

Referencias

Alliez, E. (1998). Sur le bergsonisme de Deleuze. En: E. Alliez (Ed.), Gilles Deleuze, une vie philosophique (pp. 243-264). París: Institut Synthélabo. Badiou, A. (1997). Deleuze. 'El clamor del ser'. Buenos Aires: Manantial. Bergson, H. (1985). La evolución creadora. Barcelona: Planeta Agostini. 
Bergson, H. (1994). Materia y memoria. Ensayo sobre la relación del cuerpo con el espiritu. Buenos Aires: Cactus.

Danowski, D. (1998). Deleuze avec Hume. En: E. Alliez (Ed.). Gilles Deleuze, une vie philosophique (pp. 191-206). París: Institut Synthélabo.

Deleuze, G. (1975). Spinoza y el problema de la expresión. Barcelona: Muchnik.

Deleuze, G. (1977). Empirismo y subjetividad. La filosofia de David Hume. Barcelona: Gedisa.

Deleuze, G. (1986). Nietzsche y la filosofía. Barcelona: Anagrama.

Deleuze, G. (1989a). Lógica del sentido. Barcelona: Paidós.

Deleuze, G. (1989b). El pliegue. Leibniz y el barroco. Barcelona: Paidós.

Deleuze, G. (1995) Proust y los signos. Barcelona: Anagrama.

Deleuze, G. (1996). El bergsonismo. Madrid: Cátedra.

Deleuze, G. (2002). Diferencia y repetición. Buenos Aires: Amorrortu Editores.

Deleuze, G. (2005a). La concepción de la diferencia en Bergson. En: La isla desierta y otros textos (pp. 45-70). Valencia: Pre-Textos.

Deleuze, G. (2005b). Conclusiones sobre la voluntad de poder y el eterno retorno. En: La isla desierta y otros textos (pp. 155-166). Valencia: Pre-Textos.

Deleuze, G. (2005c). Francis Bacon. Lógica de la sensación. Madrid: Arena Libros.

Deleuze, G. (2008). Kant y el tiempo. Buenos Aires: Cactus.

Deleuze, G. \& Guattari, F. (1985). El Anti Edipo. Capitalismo y esquizofrenia. Barcelona: Paidós.

Deleuze, G. \& Guattari, F. (1988). Mil mesetas. Capitalismo y esquizofrenia. Barcelona Paidós.

Deleuze, G. \& Guattari, F. (1993). ¿Qué es la filosofía? Barcelona: Anagrama.

Hegel, G. W. F. (1980). Logique et métaphysique (Iéna 1804-1805). París: Gallimard.

Heidegger, M. (1971). Nietzsche. Iy II. (Trad. P. Klossowski). París: Gallimard. Heidegger, M. (2013). Nietzsche. Barcelona: Ariel Filosofía.

Mengue, P. (2008). Deleuze o el sistema de lo múltiple. Buenos Aires: Las Cuarenta.

Nietzsche, F. W. (1932). El eterno retorno. Obra póstuma (1871-1888). Madrid: Aguilar. 
Nietzsche, F. W. (1986). El gay saber. (Trad. L. Jiménez Moreno). Madrid: Colección Austral.

Nietzsche, F. W. (2003). Así habló Zaratustra. (Trad. A. Sánchez Pascual). Madrid: Alianza.

Nietzsche, F. W. (2008). Fragmentos póstumos (1875-1882) (Vol. II). Madrid: Tecnos.

Orlandi, L. (1998). Lignes d'action de la différence. En: E. Alliez (Ed.), Gilles Deleuze, une vie philosophique (pp. 55-68). París: Institut Synthélabo.

Sauvagnargues, A. (2006). Deleuze. Del animal al arte. Buenos Aires: Amorrortu. Sloterdijk, P. (2011). Sin salvación. Tras las huellas de Heidegger. Madrid: Akal.

Smith, C. (2015). Traveser le structuralisme avec Deleuze et Lyotard. En: C. Enaudeau \& F. Fruteau de Laclos (Eds.), Différence, différend: Deleuze et Lyotard (pp. 31-48). Cerisy: Encre Marine.

Whitehead, A. N. (1956). Proceso y realidad. Buenos Aires: Losada. 